\title{
Mendidik Anak Era Digital di Perguruan Muhammadiyah Parakan Tangerang Selatan
}

\author{
Heni Ani Nuraeni ${ }^{* *}$ dan Lelly Qadariah ${ }^{1}$ \\ ${ }^{1}$ Universitas Muhammadiyah Prof. Dr. Hamka, Jl. Tanah Merdeka, Jakarta Timur, Indonesia, 13830 \\ Email: henianinuraeni@uhamka.ac.id
}

\begin{abstract}
Abstrak
Era digital merupakan era teknologi komunikasi. Teknologi komunikasi yang sering digunakan oleh anakanak sampai orang dewasa adalah gadget. Salah satu dampak negatif gadget adalah membentuk anak-anak maupun remaja mempunyai karakter yang individualis. Mareka sibuk dengan gadget sehingga melupakan tugas nya untuk belajar. Hal inilah yang dikhawatirkan guru maupun orang tua ketika anaknya bermain gadget. Guru maupun orang tua mengalami masalah dalam mencegah murid maupun anaknya dalam penggunaan gadget. Oleh karena itu, diperlukan wawasan yang luas untuk mengatur penggunaan teknologi komunikasi. Hal inilah yang menjadi dasar kerja sama antara Uhamka dan perguruan Muhammadiyah Parakan untuk mengadakah wokshop mengenai mendidik anak era digital. Target yang diharapkan dari workshop ini adalah bertambahnya wawasan guru-guru dan orang tua murid Muhammadiyah Parakan mengenai mendidik anak era digital. Dengan adanya workshop ini diharapkan guru-guru dan orang tua murid perguruan Muhammadiyah Parakan dapat mengimplementasikan dalam kehidupan sehari-hari.
\end{abstract}

Kata kunci: mendidik anak, era digital, gadget

\begin{abstract}
The digital age is the era of communication technology. Communication technology that is often used by children to adults is a gadget. One of the negative effects of gadgets is that children and adolescents have individualistic characteristics. They are so busy with their gadgets that they forget about their work to study. This is what worries both teachers and parents when their children play gadgets. Both teachers and parents have problems in preventing students and their children from using gadgets. Therefore, broad insight is needed to regulate the use of communication technology. This is the basis of the collaboration between Uhamka and Muhammadiyah Parakan colleges to hold a workshop on educating children of the digital age. The expected target of this workshop is to increase the insight of teachers and parents of Muhammadiyah Parakan students about educating children in the digital age. With this workshop it is hoped that teachers and parents of Muhammadiyah Parakan colleges can implement it in daily life.
\end{abstract}

Keywords: educate children, the digital age, gadget

Format Sitasi: Nuraeni, H.A. \& Qadariah, L. (2020). Mendidik Anak Era Digital Di Perguruan Muhammadiyah Parakan Tangerang Selatan. Jurnal SOLMA, 09(1), 26-32. Doi: http://dx.doi.org//10.29405/solma.v9i1.2941

Diterima: 18 Januari 2019 | Revisi: 11 Maret 2020 | Dipublikasikan: 30 April 2020

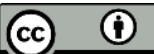

(C) 2020 Oleh authors. Lisensi Jurnal Solma, LPPM-Uhamka, Jakarta. Artikel ini bersifat open access yang didistribusikan di bawah syarat dan ketentuan Creative Commons Attribution (CC BY) license. (http://creativecommons.org/licenses/by/4.0/). 


\section{PENDAHULUAN}

Saat ini pendidikan di era digital sangatlah pesat. Kemajuan dalam bidang teknologi tidak hanya dinikmati oleh orang dewasa saja, anak-anak usia sekolah dasar juga sudah bisa menikmati dari hasil perkembangan teknologi saat ini (Putri, 2018). Menurut Pebriana (2017) teknologi selalu meluncurkan berbagai jenis fitur baru dari hari ke hari. Kebutuhan teknologi merupakan salah satu kebutuhan penting saat ini. Hal ini disebabkan karena teknologi sangat dibutuhkan khalayak umum.

Teknologi komunikasi yang akrab disebut dengan gadget merupakan salah satu sarana komunikasi yang banyak digunakan dari tahun ke tahun. Teknologi tersebut merupakan alat untuk mewujudkan bangsa yang cerdas dan maju (Sembiring, 2014b).

Internet dapat memberikan manfaat besar bagi pendidikan, penelitian, niaga, dan aspek kehidupan lainnya. Kita harus mendorong remaja dan anak-anak untuk menggunakan internet sebagai alat yang penting untuk membantu pendidikan, meningkatkan pengetahuan, dan memperluas kesempatan serta keberdayaan dalam meraih kualitas kehidupan yang lebih baik (Sembiring, 2014a).

Derasnya arus komputer disadari atau tidak telah membentuk anak anak hingga remaja mempunyai karakter yang indiviadulis, yaitu mengedepankan diri sendiri sehingga memiliki kepekaan sosial yang rendah. Menurut Satriawan (2012) kehidupan globalisasi masa sekarang ini nilai moral, kesusilaan, kebiasaan serta perintah atau larangan dalam keagamaan sering kali diabaikan oleh masyarakat termasuk remaja, hal ini dapat dilihat dalam kehidupan sehari-hari seringkali terjadi kejadian-kejadian yang menunjukkkan mulai melunturnya nilai-nilai moral dan kepekaan sosial. Kini anak-anak hingga remaja lebih terbiasa dengan telepon seluler dan komputer pribadi (Pramiyanti, Putri, \& Nureni, 2014). Telepon seluler dan komputer pribadi bukan lagi barang yang aneh bagi anak sekarang. Hal ini terjadi bagi murid di kawasan perguruan Muhammadiyah parakan, tangerang selatan.

Menurut Daeng, Mewengkang, \& Kalesaran (2017) dalam pengaplikasiannya telepon seluler tersebut sangat membantu untuk mengeksplorasi berbagai pengetahuan baru dan menunjang berbagai aktivitas khususnya ketika berada di kampus dan dalam kegiatan perkuliahan, namun belum tentu semua yang diakses dalam telepon seluler adalah hal yang baik. Telepon seluler tersebut sudah biasa mereka gunakan untuk bermain game, atau melihat konten-konten yang lain (konten untuk orang dewasa misalnya), dimana mereka belum pantas untuk melihatnya maupun mempelajarinya. Namun demikian, 
apakah murid Taman Kanak-Kanak hingga Sekolah Menengah Kejuruan di Perguruan Muhammadiyah Parakan dalam menggunakan telepon seluler dalam pengawasan guru? Dalam bentuk pengawasan yang seperti apa? Hal inilah yang perlu diperhatikan oleh sekolah maupun orang tua. Oleh karena itu diperlukan wawasan yang luas penggunaan telepon seluler maupun komputer supaya digunakan anak aman dari konten- konten yang tidak sesuai dengan perkembangan mereka.

Pimpinan daerah Aisyiyah dalam bidang pendidikan dasar dan menengah bekerja sama dengan Universitas Muhammadiyah Prof. Dr. Hamka mengadakan workshop dan pelatihan tentang mendidik anak di era digital. Workshop ini diperuntukan bagi guru taman kanak-kanak, guru sekolah dasar, guru sekolah menengah pertama, guru sekolah menengah kejuruan, dan orang tua murid, yang ada di Perguruan Muhammadiyah Parakan yang ada di Tangerang Selatan.

\section{MASALAH}

Untuk meningkatkan pengetahuan dan wawasan tentang mendidik anak era digital, maka dipandang perlu guru-guru dan orang tua murid mempunyai kompetensi dalam mendidik anak era digital. Akan tetapi sebagaimana dikemukakan sebelumnya guru-guru dan orang tua murid di Perguruan Muhamadiyah Parakan minim dalam mendidik anak era digital.

Selanjutnya dapat diidentifikasi permasalahan untuk memiliki pengetahuan dan wawasan tentang mendidik anak era digital, sebagai berikut:

a. Memiliki kemampuan dan semangat yang tinggi untuk belajar.

b. Memiliki sikap disiplin dan tidak mudah bosan dalam menasihati anak didik atau anak sendiri.

c. Memiliki ilmu agama yang cukup dalam mendidik anak era digital.

d. Mampu menggunakan gadget dan aplikasi lain yang berhubungan dengan teknologi.

e. Memiliki kemampuan menangkal konten-konten yang tidak baik bagi anak.

f. Memiliki wawasan dan pengetahuan lain yang berhubungan dengan mendidik anak era digital.

Dari identifikasi yang dikemukakan di atas, pada umumnya para peserta hanya memiliki kemampuan dan semangat yang tinggi untuk belajar dan kemungkinan menggunakan gadget sebatas Whatsapp. Sebagian belum memiliki belum memiliki kriteria yang teridentifikasi tersebut. Oleh karena itu, bersama mitra (Perguruan Muhammadiyah Parakan) memiliki kemampuan dalam mendidik anak era digital. Untuk memiliki 
kemampuan ini maka diadakan wokshop. Workshop ini ditujukan untuk guru-guru dan orang tua murid supaya memiliki kemampuan mendidik anak era digital, agar anak-anak tidak terpengaruh faktor negatif dan gadget.

\section{METODE PELAKSANAAN}

Untuk tercapainya maksud dan tujuan serta target pengabdian masyarakat, maka kami mengadakan wokshop tentang mendidik anak era digital dengan metode pendekatan sebagai berikut:

a. Memberikan motivasi agar peserta memperkuat kemauan dan semangat belajar yang tinggi, serta bersikap sungguh-sungguh dan disiplin yang tinggi.

b. Memberikan wawasan tentang peran keluarga di era digital.

c. Memberikan keterampilan tentang menghindari konten-konten yang tidak pantas untuk perkembangan anak.

d. Memberikan motivasi supaya menghindari kebosanan dalam mendidik anak era digital.

\section{HASIL DAN PEMBAHASAN}

Sesuai dengan program pengabdian dan pemberdayaan kepada masyarakat yang telah direncanakan, maka target luaran yang dicapai berupa produk dan jasa, yaitu:

a. Produk : terbentuknya guru-guru dan orang tua murid yang memiliki kemampuan mendidik anak era digital

b. Jasa : tersosialisanya mendidik anak era digital yang sangat penting di era digital.

Evaluasi produk dan jasa tersebut dilakukan melalui workshop, sekurang-kurangnya 60-70 \% para peserta workshop mampu menguasainya. Respon peserta lebih besar pada workshop mendidik anak era digital.

Dalam pelaksanaan workshop ini, guru TK hingga SMK Perguruan Muhammadiyah Parakan dan orang tua murid akan bertindak sebagai peserta aktif partisipatoris. Selain mendengarkan uraian dari narasumber, peserta workshop dan pelatihan akan diberikan kesempatan untuk belajar langsung mengenai pengaruh teknologi bagi tumbuh kembang anak, dampak negatif perkembangna teknologi, dan cara menghindarkan anak dari dampak buruk perkembangan teknologi, belajar juga tentang tips mendidik anak era digital. Dengan konsep learning by doing (belajar sambil mempraktekkan), pengetahuan dan keterampilan mengenai mendidik anak era digital. Menurut Kusmanto, Suparni, \& Sarwanto (2014) dengan learning by doing siswa mengetahui tidak hanya teoritis tetapi 
juga secara praktis. Kemudian Konstruktivisme yang mengatakan bahwa pembelajaran akan berlangsung efektif apabila siswa terlibat langsung dalam tugas-tugas autentik yang berhubungan dengan konstek yang bermakna (Nur, 2001).

Untuk lebih jelasnya, berikut disertakan kerangka pikir program pengabdian masyarakat "Mendidik Anak Era Digital di Perguruan Muhammadiyah Parakan, Tangerang Selatan.

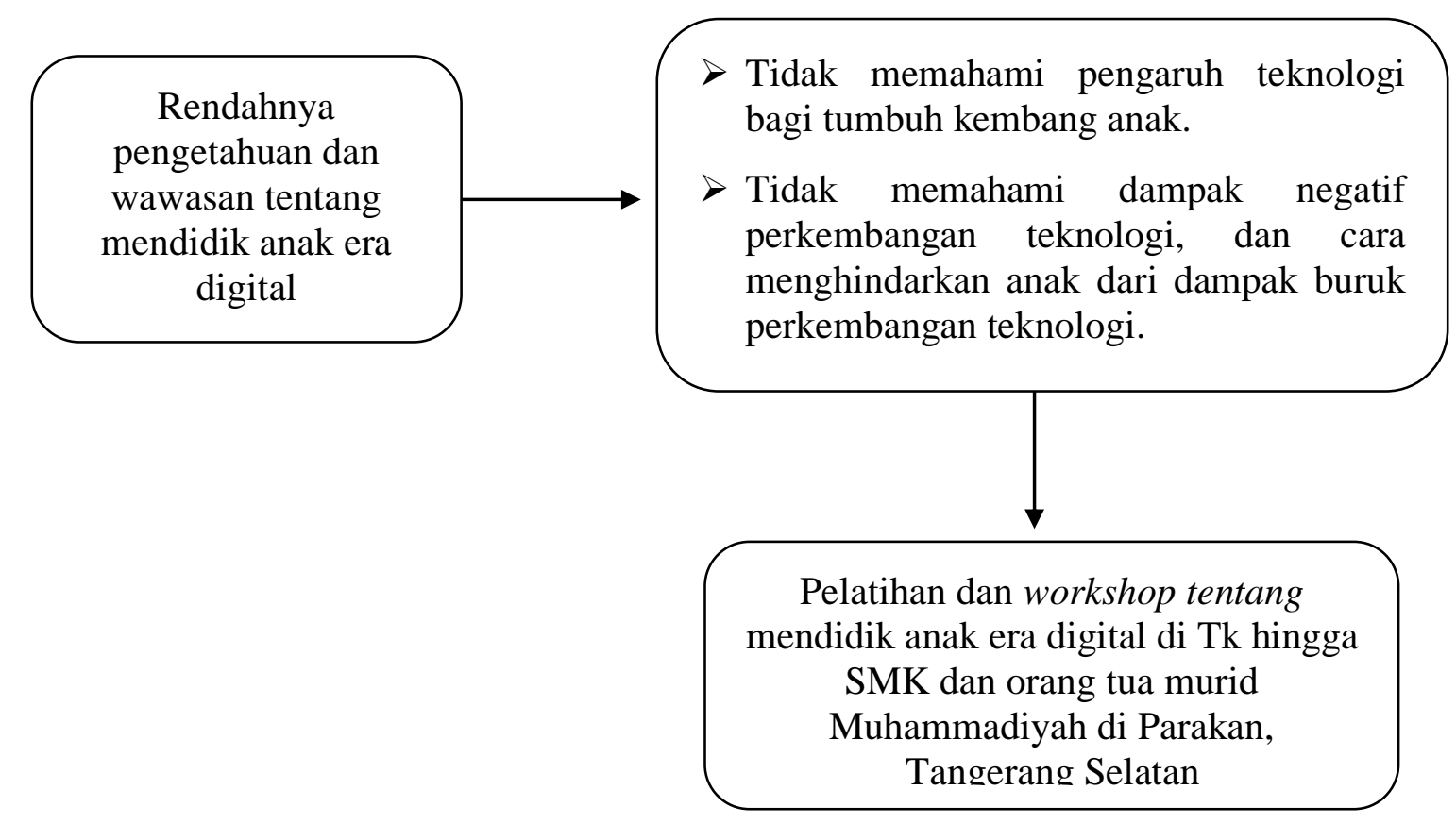

Gambar 1. Kerangka Berfikir

Dalam workshop tersebut diberikan tips mendidik anak era digital menurut Elly Risman; Safiera (2016). Tips tersebut diantaranya:

1. Tanggung jawab penuh. Peran ibu dalam pola asuh anak hal yang utama, dan peran ayah tidak kalah pentingnya. Jadi antara ayah dan ibu harus memiliki pandangan yang sama, yaitu sama-sama bertanggung jawab atas jiwa, tubuh, pikiran, keimanan, kesejakteraan anak secara utuh.

2. Kedua, kedekatan. Kedekatan ayah dan ibu ini bukan hanya kedekatan kulit ke kulit, melainkan jiwa ke jiwa. Artinya ayah dan ibu tidak hanya sering memeluk sang anak namun juga harus dekat secara emosional.

3. Ketiga, harus jelas tujuan pengasuhan. Orang tua mulai merumuskan tujuan pengasuhan sejak anak dilahirkan. Perlu membuat kesepakatan bersama, proritas apa saja yang diberikan kepada anak dan bagaimana cara pendekatannya. 
4. Keempat, berbicara baik-baik. Orang tua harus berbicara baik-baik pada anak, tidak boleh bohong, lupa membahas keunikan anak serta perlu membaca bahasa tubuh dan perasaan anak.

5. Kelima, mengajarkan agama, menjadi kewajiban orang tua untuk mengajarkan anakanaknya tentang agama, pendidikan agama perlu ditanamkan sejak dini. Dalam hal ini, mengajarkan agama tidak terbatas pada bisa membaca Al-quran, akan tetapi bagaimana anak menyukai aktivitas tersebut.

6. Keenam, persiapkan anak masuk pubertas, kebanyakan orang tua malu membicarakan masalah seks. Menurut Elly pembicaraan justru dimulai sejak dini dengan bahasa mengikuti usianya.

7. Ketujuh, persiapkan anak masuk era digital. Mengajarkan anak bahwa penggunaan gadget ada waktunya dan memilki batasan untuk itu. Akses internet perlu dibatasi untuk mencegah anak melihat situs yang tidak diinginkan.

\section{KESIMPULAN}

Dari keseluruhan peserta yang telah mengikuti workshop ini, wawasannya tentang mendidik anak era digital sangat baik karena mendapatkan persentase sebesar tercapai 83\%. Dan sebanyak $87 \%$ peserta pelatihan merasa puas atas pelaksanaan wokshop ini.

\section{UCAPAN TERIMAKASIH}

Terimakasih kepada LPPM (Lembaga Penelitiandan Pengabdian Masyarakat) sebagai pemberi dana dalam kegiatan workshop tentang Mendidik Anak Era Digital di Perguruan Muhammadiyah Parakan, Tangerang Selatan. Terimakasih kepada pimpina Perguruan Muhammadiyah Parakan sebagai mitra dalam kegiatan dan membantu dalam proses kegiatan wokshop tentang Mendidik Anak Era Digital di Perguruan Muhammadiyah Parakan, Tangerang Selatan.

\section{DAFTAR PUSTAKA}

Daeng, I. T. M., Mewengkang, N. ., \& Kalesaran, E. R. (2017). Penggunaan Smartphone Dalam Menunjang Aktivitas Perkuliahan Oleh Mahasiswa Fispol Unsrat Manado. EJournal Acta Diurna, VI(1), 1-15.

Kusmanto, A., Suparni, \& Sarwanto. (2014). Pendekatan Learning By Doingdalam Pembelajaran Fisika Dengan Media Riil Dan Multimedia Interaktif Ditinjau Dari Kreativitas Dan Motivasi Berprestasi. Jurnal Inkuiri, 3(3), 65-74.

Nur, M. (2001). Media Pengajaran dan Teknologi untuk Pembelajaran. Surabaya: Usaha Nasional. 
Pebriana, P. H. (2017). Jurnal Obsesi: Jurnal Pendidikan Anak Usia Dini Analisis Penggunaan Gadget terhadap Kemampuan Interaksi Sosial. Jurnal Pendidikan Anak Usia Dini, 1(1), 1-11. https://doi.org/10.31004/obsesi.v1i1.26

Pramiyanti, A., Putri, I. P., \& Nureni, R. (2014). Motif remaja dalam menggunakan media baru (studi pada Remaja di Daerah Sub-Urban Kota Bandung). KomuniTi, 6(2), 95103.

Putri, D. P. (2018). Pendidikan Karakter Pada Anak Sekolah Dasar Di Era Digital. ARRIAYAH: Jurnal Pendidikan Dasar, 2(1), 37-50. https://doi.org/10.29240/jpd.v2i1.439

Safiera, A. (2016). 7 Tips Pengasuhan Anak di Era Digital dari Psikolog Elly Risman. Retrieved from https://wolipop.detik.com/parenting/d-3219694/7-tips-pengasuhananak-di-era-digital-dari-psikolog-elly-risman

Satriawan, D. (2012). Hubungan Antara Anomie dengan Kepekaan Sosial pada Remaja. Naskah Publikasi. Surakarta: Universitas Muhammadiyah Surakarta.

Sembiring, T. (2014a). Kominfo Dorong Anak-anak Remaja gunakan internet untuk membantu pendidikan. Retrieved from https://kominfo.go.id/index.php/content/detail/3835/Kominfo+Dorong+Anakanak+Remaja+gunakan+internet+untuk+membantu+pendidikan/0/berita_satker

Sembiring, T. (2014b). Riset Kominfo dan UNICEF Mengenai Perilaku Anak dan Remaja Dalam Menggunakan Internet. Seminar Sehari Internasional Penggunaan Media Digital Di Kalangan Anak Dan Remaja Di Indonesia. Retrieved from https://kominfo.go.id/content/detail/3834/siaran-pers-no-17pihkominfo22014tentang-riset-kominfo-dan-unicef-mengenai-perilaku-anak-dan-remaja-dalammenggunakan-internet/0/siaran_pers 